\title{
Parents' Social Validity Appraisals of Early Childhood Intervention Practice Guides
}

\author{
Carl J. Dunst ${ }^{1}$ \\ ${ }^{1}$ Orelena Hawks Puckett Institute, Asheville and Morganton, NC, USA \\ Correspondence: Carl J. Dunst, Orelena Hawks Puckett Institute, 128 S. Sterling Street, Morganton, NC, 28655, \\ USA. Tel: 1-828-432-0065. E-mail: cdunst@puckett.org
}

Received: June 5, 2017

Accepted: June 15, 2017

Online Published: July 4, 2017

doi:10.5539/jedp.v7n2p51

URL: http://doi.org/10.5539/jedp.v7n2p51

\begin{abstract}
Findings from three field-tests of parents' ratings of early childhood intervention practice guides are reported. Results from the first field-test were used to inform changes to the practice guides in the second field-test, and results from the second field-test were used to inform changes to the practice guides in the third field-test. Parents' judgments of the practice guide designs and their social validity appraisals of the practice guide intervention activities and child outcomes were correlated with parent-informed improvements in the intervention materials. The results add to the knowledge base in terms of how parent-informed improvements to the practice guides are related to product design judgments and the social validity appraisals of the importance and acceptability of early childhood intervention materials.
\end{abstract}

Keywords: early childhood intervention, parent practice guides, product design judgments, social validity appraisals

\section{Introduction}

Early childhood intervention includes the learning experiences and opportunities used with infants, toddlers, and preschoolers to promote and enhance the children's development (Dunst \& Espe-Sherwindt, 2017; Groark, Eidelman, Maude, \& Kaczmarek, 2011; Guralnick, 2016; McWilliam, 2015). Early childhood intervention practitioners often support and strengthen parents' and other primary caregivers' abilities to use these experiences and opportunities to promote the learning and development of their young children (e.g., Acar \& Akamoğlu, 2014; Bernheimer \& Keogh, 1995; Friedman, Woods, \& Salisbury, 2012). There is, however, considerable variability in the extent to which parents use the experiences and opportunities as early childhood intervention practices with their children (Halgunseth, 2009; Korfmacher et al., 2008; Roggman et al., 2016).

Among the many reasons parents use or do not use early childhood intervention practices with their children are their beliefs about the importance and acceptability of the practices and the intended child outcomes of the practices (e.g., Dunst, Trivette, Prior, Hamby, \& Embler, 2013b; Reimers \& Wacker, 1988). These types of beliefs or subjective judgments have been described as social validity appraisals (Foster \& Mash, 1999). As noted by Strain, Barton, and Dunlap (2012), an intervention practice is not likely to be used by a parent (or a practitioner) if it is not considered worth the time and effort to use. This was demonstrated in a study by Dunst, Raab, and Hamby (2016) where parents' social validity appraisals of interest-based child language learning practices were related to the fidelity of use of the practices, where fidelity of use of the practices in turn was related to improvements in the children's language development.

Cognitive appraisals of the design characteristics of materials or products also influences people's beliefs about the usability of different products and materials (Bloch, 1995). This has been described as the aesthetics-usability effect (Lidwell, Holden, \& Butler, 2003). Research on the design properties (attractiveness, appearance, organization, aesthetics, etc.) of a product indicates that design matters a great deal when a person does or does not judge products, materials, etc., as having personal benefit or usability (e.g., Hamborg, Hülsmann, \& Kaspar, 2014; Seva, Gosiaco, Santos, \& Pangilinan, 2010; Sonderegger \& Sauer, 2010; Spague, Pennefather, Marquez, Yeaton, \& Marquez, 2011). 
The study described in this paper is part of a line of research and practice investigating parents' and practitioners' judgments and appraisals of early childhood intervention practice guides where end-user suggestions and feedback were used to improve the design, organization, and content of the intervention materials (e.g., Dunst, 2017; Dunst \& Hamby, 2017; Dunst, Trivette, Prior, Hamby, \& Embler, 2013a; Trivette, Dunst, Masiello, Gorman, \& Hamby, 2009). This brief report includes findings from three field-tests, where results from each field-test were used to inform changes and improvements in next generation practice guides.

Parents in all three field-tests selected from among a list of practice guides to review and make social validity appraisals of the importance and acceptability of both the practice guide intervention activities and child outcomes. The parents also made judgments of the attractiveness and appeal of the practice guide design. The progressive changes and improvements in the practice guides made in response to parent feedback were expected to be related to increases in parents' judgments of the importance, acceptability, and design features of the intervention materials. Exploratory structural equation modeling was used to trace the pathways of influence from improvements to the practice guides to the judgments of the attractiveness and appeal of the interventions materials to parents' social validity appraisals of the practice guide intervention activities and then to the social validity appraisals of the practice guide child outcomes.

\section{Method}

\subsection{Participants}

The participants were 173 parents and other primary caregivers of infants, toddlers, and preschoolers involved in early childhood intervention programs throughout the United States. The parents were recruited through parent organizations and early childhood programs and by announcements on parent organization websites and listserves.

The participants' children were receiving early childhood intervention because of identified disabilities, developmental delays, or because they were at-risk for poor developmental outcomes for medical (e.g., low birth weight) or socio-environmental (lower family socioeconomic status) factors. Forty-two percent of the children were involved in birth to age three early intervention or Early Head Start programs, and $58 \%$ of the children were involved in age three to five year old early childhood-special education or Head Start programs.

\subsection{Practice Guides}

The practice guides are formatted in similar ways. Each practice guide includes a description of an intervention practice and the intended benefits or outcomes of the practice, a description or list of activities (methods, strategies, etc.) for a parent to use a practice with his or her child, a vignette of parents using a practice with their children, and a list of three outcome indicators for determining if the practice guide activities had intended child benefits. Lessons learned from the first field-test informed changes and improvements in the practice guides in the second field-test, and lessons learned from both the first and second field-tests informed changes and improvements in the practice guides in the third field-test. The latter involved captioned videos of parents using the practices with their children and an external link to other resources for using the practice to promote child learning and development. Figure 1 shows one of the practice guides evaluated by parents in the third field-test.

\subsection{Procedure}

Invitations to participate in the field-tests were posted on parent and early child intervention organization websites, on parent organization listserves, and parent organization web-based newsletters. Requests were also sent to early childhood program directors who were asked to distribute the invitations to interested parents.

The invitations included a description of the purpose of the field-tests and instructions for choosing and reviewing a practice guide. The respondents were asked to read the practice guide with a specific focus on the practice guide activities and intended child outcomes. The invitation also included a web-based link to the field-test survey for respondents to evaluate the practice guides.

The survey included eight parent appraisal items, space for making comments or suggestions for improving the practice guides, a question about the age of the parent's child, and a question about their child's early childhood intervention program. The survey included items measuring parents' appraisals of the practice guide design, practice guide intervention activities, and practice guide child outcomes. The parent appraisal items included four items measuring the social validity of the practice guide intervention activities (e.g., "The practice would easily fit into my everyday schedule"; "The practice would be worth my time and effort to use"), three social validity items measuring the intended child outcomes of the practice (e.g., "The practice would help my child 
learn"; "The practice guide activities would be interesting to my child"), and one program design item ("The practice guide format is both attractive and appealing"). The eight items were each rated on a 5-point scale ranging from Do Not Agree at All to Agree a Great Deal with the survey statements.

\section{Learning Comes Naturally}

Parents can use the everyday activities in their homes and communities to support their children's participation in activities, children's attempts to interact with people or materials, and their efforts to do new things. You can encourage your child's participation and learning during everyday activities by providing your child opportunities to do what he or she can and likes to do during everyday activities, responding positively to your child's attempts to interact with you and others, and helping your child do new and different things.

Learning Guide: Encouraging Your Child's Participation and Learning

- Watch your child during everyday activities to find out what he or she likes to do and the things he or she is able to do. Notice the objects, people, activities, and actions that are your child's favorite things to do, get your child to smile or laugh, be excited, or stick to an activity. Watch for the things your child can do that help him or her participate in different activities.

- Provide your child frequent opportunities to be involved in activities that match the things he or she is able to do and likes to do. Use toys and materials that can capture your child's attention and interest. During the activities, give your child lots of opportunities and enough time to try to start interactions with toys, materials, you, or others.

- While your child is involved in the interest-based activities, notice what captures his or her attention. Pay particular attention to how your child starts to do something on his or her own, tries to start interactions with you or other people, or starts to play with toys and other objects in the activities.

- As soon as you notice your child starting to interact with people or materials in an activity, encourage your child to keep interacting by responding positively to him or her. You can show your enthusiasm and pleasure with

your child's actions, join in the activity and take turns with your child, repeat your child's actions, or say something positive about what your child does.

- Encourage your child to stay involved in an activity by continuing to provide interesting materials and responding right away to his or her actions. Try to match the intensity of your response to the level of your child's behavior.

- Consider your child's special characteristics that influence how he or she participates in the activity. Give your child different types and the amount of support he or she needs to participate. For example, you might use a special seat that supports your child when interacting with toys. Or you might help your child physically by holding a toy so your child can reach it.

- During the activities, encourage your child to try to do something slightly new or different. Praise your child for trying new things, encourage your child to vary his or her behavior, show him or her how to do something a little bit differently, or add toys or materials that encourage your child to do something new or different. Give your child plenty of opportunities to practice things he or she is just learning to do in the activities.

\section{A Quick Peek}

Pilar knew that her daughter Esme loved putting things in containers and doing activities together, especially helping with chores. Esme was excited when Pilar suggested that it was time to take clothes out of the dryer. "I do it! I do it," Esme exclaimed. Together they started taking the clothes out of the dryer. Pilar saw that Esme named the owner of the clothing as she dropped each piece in the laundry basket. "Mami. Papi. Esme," she would say. Pilar smiled and repeated the names Esme said each time she put something in the basket. Then as Esme dropped a pair of her pants into the basket and said, "Esme," Pilar responded with "Esme's pants." Esme grinned and reached for another pair of pants, saying "Esme's pants," as she handed them to Pilar. Pilar said, "Yes. Esme's pants. Esme's pink pants." Esme laughed with delight and said, "Pink pants. Pink pants. Esme's pink pants." Pilar continued to help Esme name the articles of clothing along with the owner as they completed the chore together.

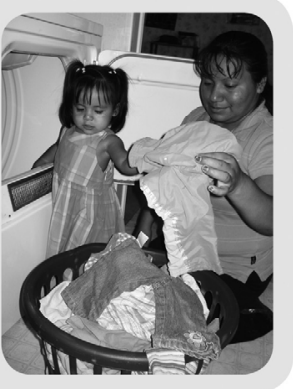

You'll know the practice is working if ...

- Your child stays involved in activities for longer periods of time

- Your child starts an interaction with you or with toys/ materials more often

- Your child does things in new and different ways during everyday activities

Learn more about naturalistic instruction from other experienced parents, your child's teacher or early interventionist, and online activities and resources such as "Getting in Step with Responsive Teaching."

\section{ECTA Center Early Childhood Technical Assistance Center http://www ectacenter org/decrp/}

Figure 1. Example of a practice guide that was the focus of parents' evaluative judgments and appraisals 


\subsection{Methods of Analysis}

Three between field-test ANOVAs with a priori tests for linear trends were used to determine if there were progressive increases in both the parents' practice guide design ratings and social validity appraisals of the practice guide intervention activities and child outcomes. The dependent variables were the average respondent ratings for the three sets of items so that the scores for all three measures ranged between 1 and 5. Cohen's $d$ effect sizes for the linear trends were the primary metrics for substantive interpretation of the results since effect sizes rather than $p$-values provide the best estimate of the magnitude of improvements to the practice guide design and content (Coe, 2002).

The fit of the hypothesized model to the pattern of relationships among the field-test variables in the exploratory structural equation model were evaluated by the Root Mean Square Error of Approximation (RMSEA), Root Mean Square Residual (RMSR), Comparative Fit Index (CFI), and Incremental Fit Index (IFI). The closer RMSEA and RMSR are to zero, and the closer CFI and IFI are to one, the better the fit of the model to the data. The standardized structural (path) coefficients were used to evaluate the direct and indirect effects of the variables in the model. These can range from -1.00 to 1.00 when the size of effect is a measure of the strength of relationships among the variables in the model.

\section{Results}

\subsection{Between Field-Test Comparisons}

The mean ratings for the practice guide design judgments and social validity appraisals are shown in Figure 2. There were between field-test differences in the mean scores for the practice guide design, $F(2,171)=8.16, p$ $=.0004$. There was also a linear increase in the parents' judgment of the practice guide design, $F(1,171), p$ $=.0000$, Cohen's $d=1.71$. Follow-up effect size calculations showed that the linear increases were primarily for the Field-Test 1 vs. Field-Test 2 and the Field-Test 1 vs. Field-Test 3 differences. The Cohen's $d$ effect sizes for these two field-test comparisons were $d=.64$ and $d=.80$, respectively, for the parents' judgments of the practice guide design, whereas the effect size for Field-Test 2 vs. Field-Test 3 was $d=.21$.

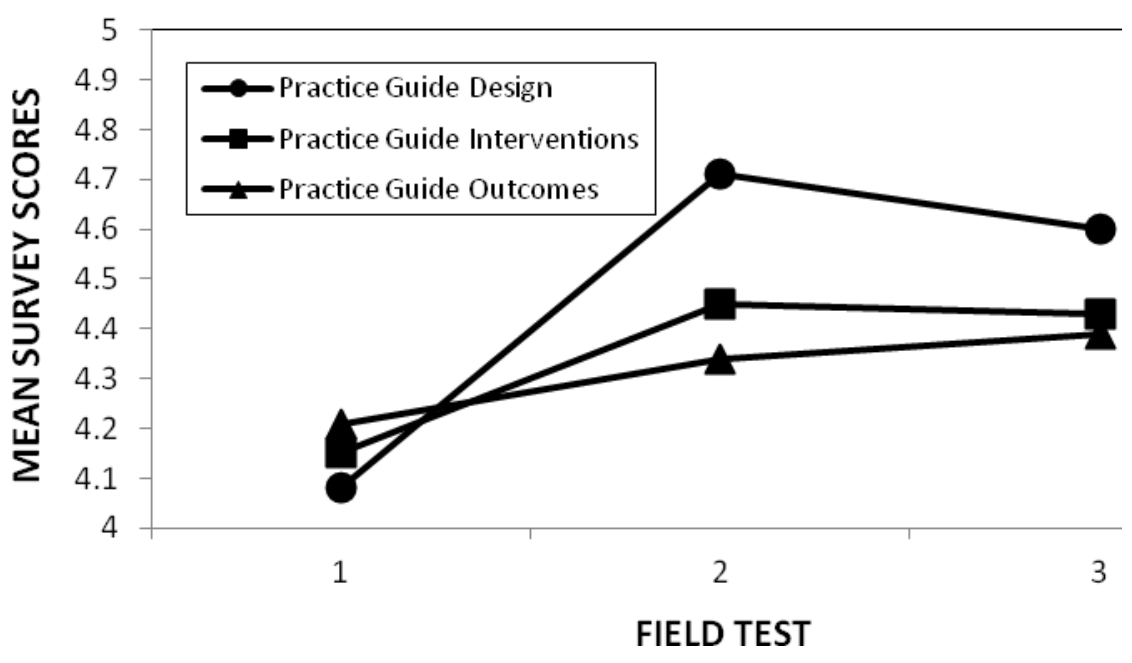

Figure 2. Parents' mean practice guide design judgments and social validity appraisals of the practice guide intervention activities and child outcomes

There were also between field-test differences in the mean scores for the parents' social validity appraisals of the practice guide intervention activities, $F(2,171)=3.38, p=.0363$, and a linear increase in the social validity scores, $F(1,170)=5.94, p=.0158, d=1.02$. Follow-up effect size calculations showed that the effect sizes for the parents' social validity appraisals of the practice guide intervention activities was $d=.46$ for Field-Test 1 vs. Field-Test 2 and $d=.49$ for Field-Test 1 vs. Field-Test 3. In contrast, the effect sizes for Field-Tests 2 vs. 3 was $d=.04$. 
There were no between field-test differences for the parents' social validity appraisals of the practice guide child outcomes, $F(2,171)=0.68, p=.5090$. There was, however, a small effect size for the linear change in the mean scores, $F(1,170)=1.31, p=.2540, d=.48$.

\subsection{Correlational Analyses}

Table 1 shows the correlations between the field-test study measures. The patterns of relationships were as expected. Improvements to the practice guides were correlated with both the practice guide design judgments and social validity appraisals of the practice guide intervention activities but not the child outcomes. Practice guide design judgments were correlated with both social validity appraisals, and the social validity appraisals of the practice guide intervention activities were correlated with social validity appraisals of the child outcomes.

Table 1. Correlations among the field-test variables

\begin{tabular}{lccc}
\hline & PG Design & \multicolumn{2}{c}{ Social Validity Appraisals } \\
\cline { 3 - 4 } Study Variables & Judgments & PG Activities & PG Outcomes \\
\hline Practice Guide (PG) Improvements & $.28^{* *}$ & $.18^{*}$ & .08 \\
Practice Guide Design & - & $.59^{* * *}$ & $.49^{* * *}$ \\
PG Intervention Activities & & - & $.68^{* * *}$ \\
PG Child Outcomes & & & - \\
\hline
\end{tabular}

${ }^{*} p<.001 .{ }^{* *} p<.0002 . * * * p<.0001$.

\subsection{Structural Equation Modeling Results}

Figure 3 shows the results from the structural equation modeling analysis. RMSEA was .03, RMSR was .02, CFI was .99, and IFI was .99 . These results indicate a good fit of the model to the relationships among the variables in the model (Table 1).

Progressive changes to the practice guides were directly related to parents' judgment of the practice guide designs, and indirectly related to parents' social validity appraisals of the practice guide intervention activities, mediated by practice guide design judgments, $\beta=.27 \times .57=.15, p=.000$. The progressive changes to the practice guides were also indirectly related to the social validity appraisals of the practice guide child outcomes mediated by both practice guide design judgments and practice guide intervention activity social validity appraisals, $\beta=.14, p=.0035$.

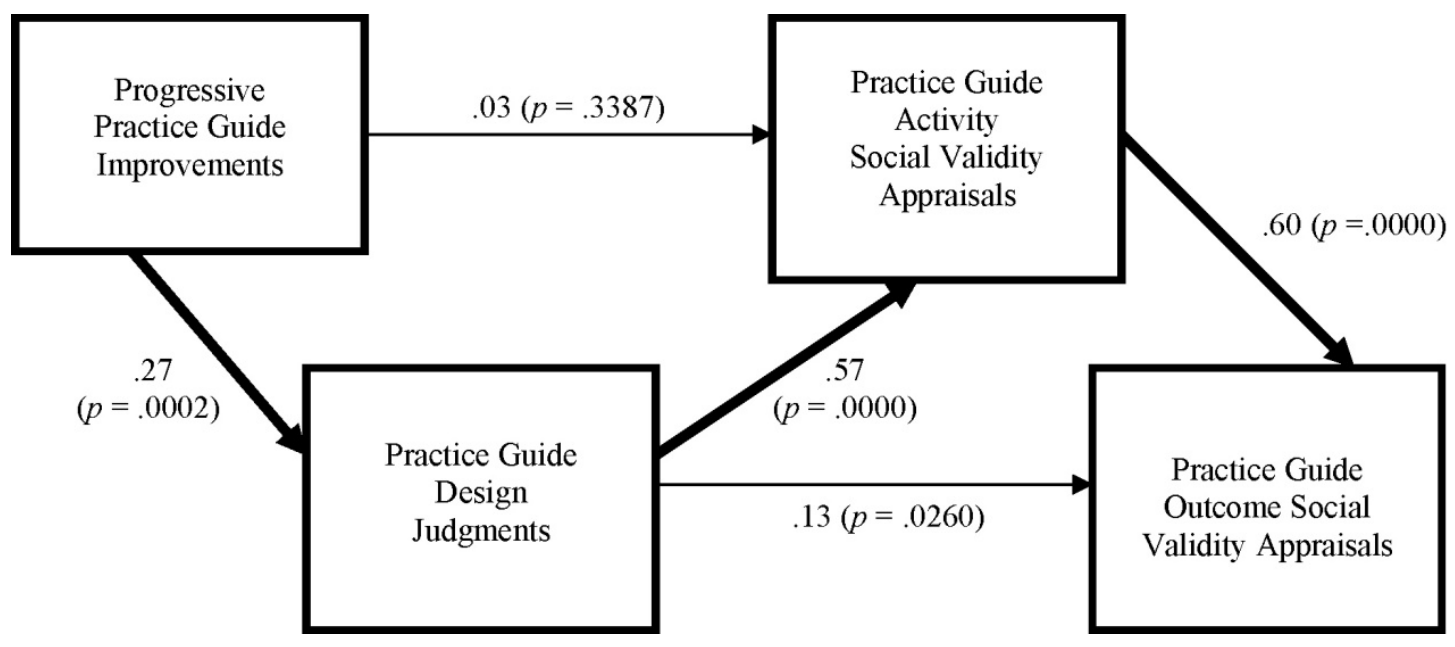

Figure 3. Pathways of relationships among the four variables in the structural equation modeling analysis Note. The main pathways in the model are in bold. 
Parents' practice guide design judgments were directly related to parents' social validity appraisals of both the practice guide intervention activities and child outcomes, although the size of effect for the relationship with the intervention activities was four times larger than those for the child outcomes. The parents' practice guide design judgments were also indirectly related to the parents' social validity appraisals of the practice guide child outcomes mediated by the social validity appraisals of the practice guide intervention activities, $\beta=.57 \times .60$ $=.34, p=.0000$. The parents' social validity appraisals of the practice guide intervention activities were directly related to their social validity appraisals of the practice guide child outcomes.

\section{Discussion}

Findings from the between field-test comparisons showed that parents' product design judgments and social validity appraisals of the practice guide intervention activities and child outcomes increased as a function of improvements to the intervention materials. Results from the structural equation modeling analyses showed that there was an adequate fit of the hypothesized model to the pattern of relationships among the field-test variables. The two sets of findings, taken together, indicate that parent-informed improvements in early childhood intervention materials in general, and the parent practice guides specifically, can enhance the usability, acceptability, and importance of intervention products, materials, and practices.

As noted earlier, the field-tests described in this paper are part of a line of research and practice investigating (a) improvements in both parent and practitioner early childhood intervention practices (Dunst, 2017; Dunst, Pace, \& Hamby, 2007; Dunst, Trivette, Gorman, \& Hamby, 2010), (b) the relationship between end-user appraisals and judgments of the practices and fidelity of use of the practices (e.g., Dunst \& Hamby, 2015; Dunst, Trivette, \& Raab, 2014), and (c) the effects of fidelity of use of early childhood intervention practices on child outcomes (Dunst et al., 2016). This study adds to this knowledge base by demonstrating that end-user appraisals and judgments of intervention practices are related in discernible ways. The structural equation modeling results, together with those found in other studies (e.g., Dunst et al., 2016; Dunst et al., 2014; Trivette, Raab, \& Dunst, 2014), also add to the knowledge base in terms of an understanding of the manner in which different types of personal beliefs influence judgments of materials and products (e.g., Dunst \& Hamby, 2017; Seva et al., 2010).

Enhancing the usability of intervention materials (Santos, Fowler, Corso, \& Bruns, 2000) and the acceptance and importance of intervention practices (Strain et al., 2012) have been "called for" to improve parents' and practitioners' adoption and use of early childhood intervention practices with infants, toddlers, and preschoolers. Santos et al. (2000), for example, noted that "we need to find ways to enhance the usability of [intervention] materials" (p. 20) so as to be acceptable to a wide range of end-users. Similarly, Strain et al. (2012) noted that improving judgments of the acceptability and importance of intervention practices can facilitate increased use of the practices. Studies like the one described in this paper contribute to these two goals by involving end-users in evaluating early childhood intervention practices and materials and making end-user-informed improvements in the practices and materials. The interested reader is referred to Rice and Valdivia (1991), Santos et al. (2000), and Springston and Champion (2004) for suggestions and guidelines for designing user friendly materials.

\section{Acknowledgments}

The field-test evaluations in this paper were supported, in part, by funding from the U.S. Department of Education, Office of Special Education Programs (Grant \# H326P120002) awarded to the University of North Carolina-Chapel Hill. The opinions expressed, however, are those of the authors and endorsement by the funder or university should not be inferred or implied.

\section{References}

Acar, S., \& Akamoğlu, Y. (2014). Practices for parent participation in early intervention/early childhood special education. International Journal of Early Childhood Special Education, 6(1), 80-101. https://doi.org/10.20489/intjecse.93010

Bernheimer, L. P., \& Keogh, B. K. (1995). Weaving interventions into the fabric of everyday life: An approach to family assessment. Topics in Early Childhood Special Education, 15, 415-433. https://doi.org/10.1177/027112149501500402

Bloch, P. H. (1995). Seeking the ideal form: Product design and consumer response. Journal of Marketing, 5(3), 16-29. https://doi.org/10.2307/1252116 
Coe, R. (2002, September). It's the effect size, stupid: What effect size is and why it is important. Paper presented at the Annual Conference of the British Educational Research Association, University of Exeter, England. Retrieved from http://www.leeds.ac.uk/educol/documents/00002182.htm

Dunst, C. J. (2017). Early childhood practitioner judgments of the social validity of performance checklists and parent practice guides. Journal of Education and Training Studies, 5(3), 176-187. https://doi.org/10.11114/jets.v5i3.2162

Dunst, C. J., \& Espe-Sherwindt, M. (2017). Contemporary early intervention models, research, and practice for infants and toddlers with disabilities and delays. In J. M. Kauffman, D. P. Hallahan, \& C. P. Pullen (Eds.), Handbook of special education (2nd ed., pp. 831-849). New York: Routledge.

Dunst, C. J., \& Hamby, D. W. (2015). Research synthesis of studies to promote parent and practitioner use of assistive technology and adaptations with young children with disabilities. In D. L. Edyburn (Ed.), Advances in special education technology: Efficacy of assistive technology interventions (Vol. 1, pp. 51-78). United Kingdom: Emerald Publishing.

Dunst, C. J., \& Hamby, D. W. (2017). Predictors of the social validity judgments of early childhood intervention performance checklists and practice guides. International Journal of Psychology and Educational Studies, 4(1), 13-20. https://doi.org/10.17220/ijpes.2017.01.002

Dunst, C. J., Pace, J., \& Hamby, D. W. (2007). Evaluation of the Games for Growing tool kit for promoting early contingency learning. Asheville, NC: Winterberry Press.

Dunst, C. J., Raab, M., \& Hamby, D. W. (2016). Interest-based everyday child language learning. Revista de Logopedia, Foniatria y Audiologia, 36, 153-161. https://doi.org/10.1016/j.rlfa.2016.07.003

Dunst, C. J., Trivette, C. M., \& Raab, M. (2014). Everyday child language learning early intervention practices. Infants and Young Children, 27(3), 207-219. https://doi.org/10.1097/IYC.0000000000000015

Dunst, C. J., Trivette, C. M., Gorman, E., \& Hamby, D. W. (2010). Further evidence for the social validity of the Center for Early Literacy Learning practice guides. CELLpapers, 5(1), 1-3. Retrieved from http://www.earlyliteracylearning.org/cellpapers/cellpapers_v5n1.pdf

Dunst, C. J., Trivette, C. M., Prior, J., Hamby, D. W., \& Embler, D. (2013a). Parents' appraisals of the animacy and likeability of socially interactive robots for intervening with young children with disabilities. Social Robots Research Reports, 2. Retrieved from http://www.socialrobots.org/SocRobotRpt_2.pdf

Dunst, C. J., Trivette, C. M., Prior, J., Hamby, D. W., \& Embler, D. (2013b). Parents' judgments of the acceptability and importance of socially interactive robots for intervening with young children with disabilities. Social Robots Research Reports, 1. Retrieved from http://www.socialrobots.org/reports.php

Foster, S. L., \& Mash, E. J. (1999). Assessing social validity in clinical treatment research issues and procedures. Journal of Consulting and Clinical Psychology, 67, 308-319. https://doi.org/10.1037/0022-006X.67.3.308

Friedman, M., Woods, J., \& Salisbury, C. (2012). Caregiver coaching strategies for early intervention providers: Moving toward operational definitions. Infants and Young Children, 25(1), 62-82. https://doi.org/10.1097/IYC.0b013e31823d8f12

Groark, C. J., Eidelman, S. M., Maude, S., \& Kaczmarek, L. (2011). Early childhood intervention: Shaping the future for children with special needs and their families. Santa Barbara, CA: Praeger.

Guralnick, M. J. (2016). Early intervention for children with intellectual disabilities: An update. Journal of Applied Research in Intellectual Disabilities, 30(2), 211-229. https://doi.org/10.1111/jar.12233

Halgunseth, L. C. (2009). Family engagement, diverse families and early childhood education programs: An integrated review of the literature. Young Children, 64(5), 56-58. Retrieved from http://search.proquest.com.libproxy.lib.unc.edu/docview/197647848/fulltextPDF/6AE90A99362645CEPQ/ 11? accountid $=14244$

Hamborg, K.-C., Hülsmann, J., \& Kaspar, K. (2014). The interplay between usability and aesthetics: More evidence for the "what is usable is beautiful" notion. Advances in Human-Computer Interaction (Article ID 946239), 2014. https://doi.org/10.1155/2014/946239 
Korfmacher, J., Green, B., Staerkel, F., Peterson, C., Cook, G. A., Roggman, L. A., ... Schiffman, R. (2008). Parent involvement in early childhood home visiting. Child and Youth Care Forum, 37(4), 171-196. https://doi.org/10.1007/s10566-008-9057-3

Lidwell, W., Holden, K., \& Butler, J. (2003). Universal principles of design. Beverly, MA: Rockport Publishers.

McWilliam, R. A. (2015). Future of early intervention with infants and toddlers for whom typical experiences are not effective. Remedial and Special Education, 36(1), 33-38. https://doi.org/10.1177/0741932514554105

Reimers, T. M., \& Wacker, D. P. (1988). Parents' ratings of the acceptability of behavioral treatment recommendations made in an outpatient clinic: A preliminary analysis of the influence of treatment effectiveness. Behavioral Disorders, 14(1), 7-15.

Rice, M., \& Valdivia, L. (1991). A simple guide for design, use, and evaluation of educational materials. Health Education Quarterly, 18, 79-85. https://doi.org/10.1177/109019819101800108

Roggman, L. A., Cook, G. A., Innocenti, M. S., Jump Norman, V., Boyce, L. K., Christiansen, K., \& Peterson, C. A. (2016). Home visit quality variations in two Early Head Start programs in relation to parenting and child vocabulary outcomes. Infant Mental Health Journal, 37(3), 193-207. https://doi.org/10.1002/imhj.21565

Santos, R. M., Fowler, S. A., Corso, R. M., \& Bruns, D. A. (2000). Acceptance, acknowledgment, and adaptability: Selecting culturally and linguistically appropriate early childhood materials. Teaching Exceptional Children, 32(3), 14-22. https://doi.org/10.1177/004005990003200303

Seva, R. R., Gosiaco, K. G. T., Santos, C. E. D., \& Pangilinan, D. M. L. (2010). Product design enhancement using apparent usability and affective quality. Applied Ergonomics, 30, 1-7.

Sonderegger, A., \& Sauer, J. (2010). The influence of design aesthetics in usability testing: Effects on user performance and perceived usability. Applied Ergonomics, 41(3), 403-410. https://doi.org/10.1016/j.apergo.2009.09.002

Spague, J., Pennefather, J., Marquez, J., Yeaton, P., \& Marquez, B. (2011). Online universal screening and behavioral progress monitoring: Assessing social validity, usability and intent to use by $K-3$ teachers. Retrieved from https://www.sree.org/conferences/2011/program/downloads/posters/162.pdf

Springston, J. K., \& Champion, V. L. (2004). Public relations and cultural aesthetics: Designing health brochures. Public Relations Review, 30, 483-491. https://doi.org/10.1016/j.pubrev.2004.08.005

Strain, P. S., Barton, E. E., \& Dunlap, G. (2012). Lessons learned about the utility of social validity. Education and Treatment of Children, 35, 183-200. https://doi.org/10.1353/etc.2012.0007

Trivette, C. M., Dunst, C. J., Masiello, T., Gorman, E., \& Hamby, D. W. (2009). Social validity of the Center for Early Literacy Learning parent practice guides. CELLpapers, 4(1), 1-4. Retrieved from http://www.earlyliteracylearning.org/cellpapers/cellpapers_v4n1.pdf

Trivette, C. M., Raab, M., \& Dunst, C. J. (2014). Factors associated with Head Start staff participation in classroom-based professional development. Journal of Education and Training Studies, 2(4), 32-45.

\section{Copyrights}

Copyright for this article is retained by the author(s), with first publication rights granted to the journal.

This is an open-access article distributed under the terms and conditions of the Creative Commons Attribution license (http://creativecommons.org/licenses/by/4.0/). 